\title{
HLA-DQB1 Haplotypes and their Relation to Oral Signs Linked to Celiac Disease Diagnosis
}

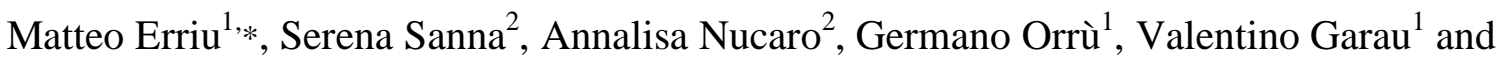 \\ Caterina Montaldo ${ }^{1}$ \\ ${ }^{I}$ Department of Surgery and Odontostomatological Sciences, University of Cagliari. Cagliari \\ ${ }^{2}$ Neurogenetic and Neuropharmacology Institute, Italian National Research Council (CNR)
}

\begin{abstract}
Objectives: Celiac disease (CD) is an autoimmune disorder that can be divided into typical and atypical forms. Atypical forms can show extraintestinal manifestations among which oral signs are very frequent. Considering that the pathogenesis of CD is related to a positivity to specific HLA-DQB1 haplotypes, we tested whether the presence of the HLA-DQB $1 * 02$ allele could be a hypothetical cause of the development of oral manifestations.

Subjects and Methods: For this study was been examined the oral condition of 98 Sardinian patients, all affected by CD and all on a gluten-free diet for at least 1 year. Then was been determined each patient's HLA-DQB1 haplotype and compared these results with clinical information.

Results: The statistical analysis evidenced that the absence of the HLA-DQB $1 * 02$ allele predisposes to oral manifestations such as dental enamel defects (DED) and recurrent aphthous stomatitis (RAS) (Pvalue=5.98x10 ${ }^{-05}, \mathrm{OR}=0.23$, CI: $(0.10$ - 0.45) per each copy of the HLA allele).

Conclusions: These results showed that the presence of the HLA-DQB $1 * 02$ allele influences the development of oral signs in a dose-dependent manner and also how the HLA haplotype connected to oral signs could have a fundamental role for the diagnosis of atypical forms of CD.
\end{abstract}

Keywords: Celiac disease, HLA, oral pathology.

\section{INTRODUCTION}

Celiac disease (CD) is an autoimmune disease linked to a permanent sensitivity to gliadin contained in alimentary gluten $[1,2]$. This condition determines chronic inflammation on intestinal mucous with consequent parietal injury [3]. The autoimmune response happens as a reaction against tissue transglutaminase autoantigen that principally damages the gastroenteric system determining global malabsorption with progressive flattening of the intestinal villi [4-6].

Celiac disease can be distinguished into different clinical forms known as classical, atypical, subclinical and latent. The classical form is characterised by intestinal symptoms as chronic diarrhea, weight loss, growth deficit, vomiting; all other symptoms from other sites determine the atypical, subclinical and latent forms [7, 8]. Atypical pattern may be often presents only by lesions in the oral mucosa or by defects in dental enamel [9].

$\mathrm{CD}$ is strictly linked to a genetic predisposition given by particular human leukocyte antigen (HLA) class II alleles, such as type 1 diabetes, rheumatoid arthritis, multiple sclerosis and Hashimoto's thyroiditis [10, 11]. Among all HLA

*Address correspondence to this author at the Via Binaghi 4, 09121 Cagliari (CA)' Tel: (+39) 070537437; Fax: (+39) 070537437;

E-mail: matteoerr@gmail.com codified antigens, $90 \%$ of celiac patients carry the HLADQB1*0201 allele (DQ2 antigen) and, if this is absent, the HLA-DQB1*0302 allele (DQ8 antigen) [12,13]. It is important to highlight that this HLA molecule is almost always cis-encoded by the DRB1*0301-DQA $1 * 0501-$ DQB $1 * 0201$ haplotype, quite common in Sardinia (39\% frequency) with one of the world's highest frequencies [13-16]. In celiac disease we can identify an activation of T cells, linked to HLA expression, in the epithelium and lamina propria of the gut, which disappears after a gluten-free diet. Recent works have shown that $\mathrm{T}$ cells do not disappear in the oral mucosa of treated celiac patients due to a still unknown mechanism [17, $18]$.

HLA typing is an important marker to confirm a diagnosis of $\mathrm{CD}$, moreover today interest is increasing regarding different clinic forms of CD linked to different HLA-DQB1 haplotypes [19].

Among all these clinical manifestations, the prevalence of $\mathrm{CD}$ is currently underestimated, since many atypical cases remain undiagnosed [20,21]. The development of serious or even fatal complications (autoimmunity, cancers) requires the earliest possible diagnosis of CD [22]. This also explains the importance of a strict gluten-free diet for celiac patients who seem to be protected against long-term complications $[23,24]$. 
Table 1. Classification of Systemic Enamel Defects in Celiac Disease, (29)

\begin{tabular}{|c|c|}
\hline Grade I & $\begin{array}{l}\text { Defects in colour of enamel: single or multiple } \\
\text { cream, yellow or brown opacities }\end{array}$ \\
\hline Grade II & $\begin{array}{l}\text { Slight structural defects: rough enamel surface, } \\
\text { horizontal grooves, shallow pits }\end{array}$ \\
\hline Grade III & $\begin{array}{c}\text { Evident strucutral defects: deep horizontal grooves, } \\
\text { large vertical pits }\end{array}$ \\
\hline Grade IV & $\begin{array}{l}\text { Severe structural defects: shape of the tooth may be } \\
\text { changed }\end{array}$ \\
\hline
\end{tabular}

Oral signs are most frequently CD symptoms, linked to atypical forms, and are represented principally by recurrent aphthous stomatitis (RAS) and dental enamel defects (DED) $[6,9,25,26]$. The aim of this study is to investigate about a possible correlation between the presence of specific HLA alleles with the presence or absence of RAS and DED.

\section{MATERIALS AND METHODS}

\section{Subjects}

For this study were analysed 98 celiac patients (23 males and 75 females), with a medium age of 35.92 years (range 7 - 77 years). All patients were typed for anti-gluten antibodies (AGA, both $\operatorname{IgA}$ and $\mathrm{IgG}$ ) and antiendomysial antibody (EMA). Intestinal damage has been graded according to the Marsh classification (type 3, type 2 and type 1 ). In order to reduce possible confounding effects or intestinal damage due to diseases other than celiac disease, patients with the type 1 and 2 of the classification were excluded before the study. For all participants the diagnosis of CD was stablished by demonstration of enteropathy with type 3 villous atrophy in a small bowel biopsy and all patients had been on a gluten-free diet for at least 1 year. Furthermore, all patients responded to a gluten-free diet, as evaluated upon further regular annual follow-ups.

An anamnestic and diagnostic case study was compiled for each patient to indicate the past or present presence of celiac oral signs, such as RAS and DED [6, 25, 26]. DED were graded 0 to IV according to Aine's classification [2729] (Table 1) while RAS linked to CD was determined by the investigation as the past presence of frequently aphtous lesions described by patients as the presence of one or more ulcers at the same time recurring at least 2 times a month, in the period before the gluten-free diet, and never more returned after 1 month of diet. The presence of these lesions was verified by evaluating the medical records of first admission.

At the time of examination, all participants were informed about the research and its purpose and gave their informed consent in accordance with the ethical standards of the Helsinki Declaration of 1975. Oral brushing was subsequently carried out on all patients, obtaining a sample for DNA extraction allowing the determianation of the HLADQB1 haplotype using the conventional PCR method [30].

\section{PCR Technique and Determination of HLA-DQB1 Genotype}

To perform the PCR for each sample, a Kit formed from a pre-formed MIX and eight couples of primers was used. Positivity or negativity of amplification performed for each couple allows the HLA-DQB1 genotype to be determined [25-26]. This set of primers will positively identify the HLADQB1 alleles corresponding to the serologically defined series HLA-DQ2, DQ3, DQ4, DQ5, DQ6, DQ7, DQ8 and DQ9, thus all combinations of DQB1 can be readily identified. DQ4, DQ5 and DQ6 were uniquely identified, whereas the DQ2 specificity was amplified by three primer mixes, DQ7 and DQ9 specificities were amplified by two primer mixes, DQ3 and DQ8 specificities were amplified by four primer mixes.

On the contrary, on examining the eight primer mixes with corresponding amplified DQB1 alleles, the first primer mix amplified allele group DQB $1 * 05$, the second amplified allele group DQB1*06, the third, the fourth and the sixth amplified allele group DQB $1 * 02$, the fourth, the fifth, sixth and seventh amplified allele group DQB $1 * 03$ and the eighth amplified allele group DQB1*04.

For all the alleles, the reaction was performed in $10.08 \mu \mathrm{l}$ reaction volumes using the mixture according to the manufacturer's instructions. The mixture contained $3 \mu \mathrm{l}$ of master mix, $5 \mu \mathrm{l}$ of DNAsi-RNAsi free water, $0.08 \mu \mathrm{l}$ of Taq polymerase and $2 \mu \mathrm{l}$ of DNA suspension, this was put into a tube containing the lyophilized primer pair. The thermocycler profile was as follows: an initial denaturation at $94^{\circ} \mathrm{C}$ for $2 \mathrm{~min}$; 10 cycles consisting of $94^{\circ} \mathrm{C}$ for $10 \mathrm{sec}$ and $65^{\circ} \mathrm{C}$ for $1 \mathrm{~min}$ and finally 20 cycles consisting of $94^{\circ} \mathrm{C}$ for 10 sec, $61^{\circ} \mathrm{C}$ for $1 \mathrm{~min}$ and $72^{\circ} \mathrm{C}$ for $30 \mathrm{sec}$. PCR products were analysed by electrophoresis on an agarose gel.

\section{Statistical Analysis}

To test the relation between the HLA haplotype and the presence of oral signs, we used a logit regression model where the outcome variable represents the presence (or absence) of the specific oral sign to be tested (DED , RAS, or both). A variable was then coded with values 0,1 or 2 if the individual carried no, one or two copies of the HLADQB $1 * 02$ allele, respectively.

\section{RESULTS}

Among the 98 patients included in this study, 38.8\% (38 persons) were affected by RAS before the gluten-free diet and $28.6 \%$ (28 patients) presented DED. Grade I type enamel defects were the only diagnosed. In total $61.2 \%$ (60 patients) of the patients showed one or more oral signs (Fig. 1).

The majority of the patients carried one $(48.0 \%)$ or two (33.7\%) copies of the HLA-DQB1*02 allele, whereas $18.3 \%$ did not carry this allele. Interestingly, we observed that most of the patients carrying one of two copies of the HLADQB $1 * 02$ allele did not show DED, and this observation was statistically significant $(\mathrm{P}=0.0003$, see Table 2). Similarly, the presence of at least one copy of the HLA allele correlates with a lower frequency of $\operatorname{RAS}(\mathrm{P}=0.002$, 


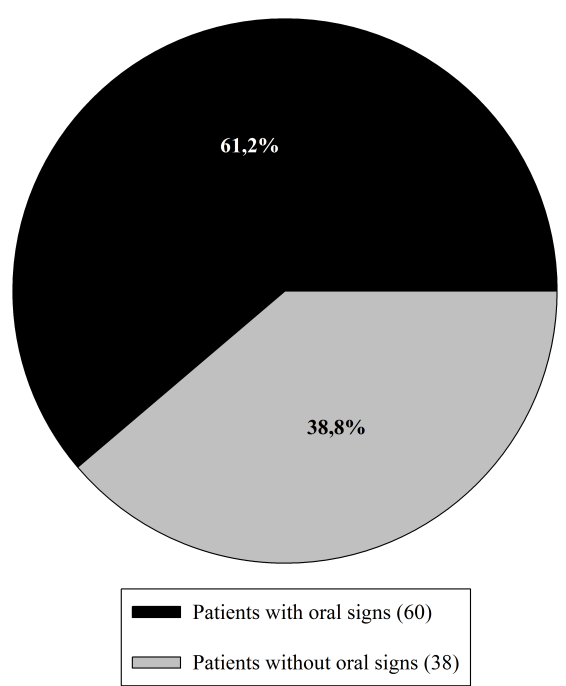

Fig. (1). Distribution of DED and RAS among the 98 examined patients.

Table 2. This Table Summarizes the Distribution of the HLA-DBQ*02 Haplotype Among Individuals Affected by DED, or RAS, or by One of these Two. For Each Oral Sign Tested, We Reported the p-Value and the Odds Ratio for Each Copy of the HLA Allele

\begin{tabular}{|c|c|c|c|c|c|c|}
\hline Copies of the HLA-DBQ $* 02$ & N Affected & N Unaffected & Affected \% & Unaffected \% & $\begin{array}{c}\text { OR } \\
(\mathrm{CI}-\mathbf{- 2 . 5 - 9 7 . 5})\end{array}$ & Pvalue \\
\hline \multicolumn{7}{|c|}{ DED } \\
\hline 0 & 12 & 6 & 0.428 & 0.085 & & \\
\hline 1 & 12 & 35 & 0.428 & 0.500 & & \\
\hline \multirow[t]{2}{*}{2} & 4 & 29 & 0.142 & 0.414 & & \\
\hline & & & & & $0.25(0.11-0.51)$ & 0.0003 \\
\hline \multicolumn{7}{|c|}{ RAS } \\
\hline 0 & 12 & 6 & 0.315 & 0.100 & & \\
\hline 1 & 19 & 28 & 0.500 & 0.467 & & \\
\hline \multirow[t]{2}{*}{2} & 7 & 26 & 0.185 & 0.433 & & \\
\hline & & & & & $0.37(0.18-0.68)$ & 0.002 \\
\hline \multicolumn{7}{|c|}{ DED or RAS } \\
\hline 0 & 18 & 0 & 0.340 & 0.000 & & \\
\hline 1 & 24 & 23 & 0.453 & 0.676 & & \\
\hline \multirow[t]{2}{*}{2} & 11 & 22 & 0.207 & 0.324 & & \\
\hline & & & & & $0.23(0.10-0.45)$ & $5.98 \times 10^{-5}$ \\
\hline
\end{tabular}

see Table 2). The statistical evidence was stronger when considering both oral signs. Indeed, all individuals who did not carry a copy of the HLA-DQB $1 * 02$ allele presented RAS or DED ( $\mathrm{P}=5.98 \times 10^{-5}$, see Table 2 and Fig. 2), while no appreciable difference was observed between those carrying one or two copies.

\section{DISCUSSION}

For modern medicine, genetic screening is becoming more important thanks to major advances in research into pathology etiology. Nowadays HLA is one of the most studied genetic loci because it is linked to many genetic diseases; among these,celiac disease is an important candidate for public health newborn genetic screening based on HLA-DQ alleles [31].
Genetic screening on HLA locus linked to celiac development will primarily eliminate the further need for the $60 \%$ of the population lacking the DQ2 and DQ8 antigens to undergo serial autoantibody testing but the aim of this work was to show how HLA could be important not just for obtaining an "exclusion diagnosis" $[32,33]$.

In recent years, the increasing detection of atypical forms of $\mathrm{CD}$, has made it necessary to find more precise early diagnostic methods that permit the underlying part of the "celiac iceberg "to be discovered [21, 34]. In this study on 98 CD patients from Sardinia we evaluated the possible relationship between the HLA haplotype and the development of oral diseases to verify the value of these oral signs as diagnostic instruments of $\mathrm{CD}$. We observed that the absence of the HLA-DQB $1 * 02$ allele is associated with the presence of 


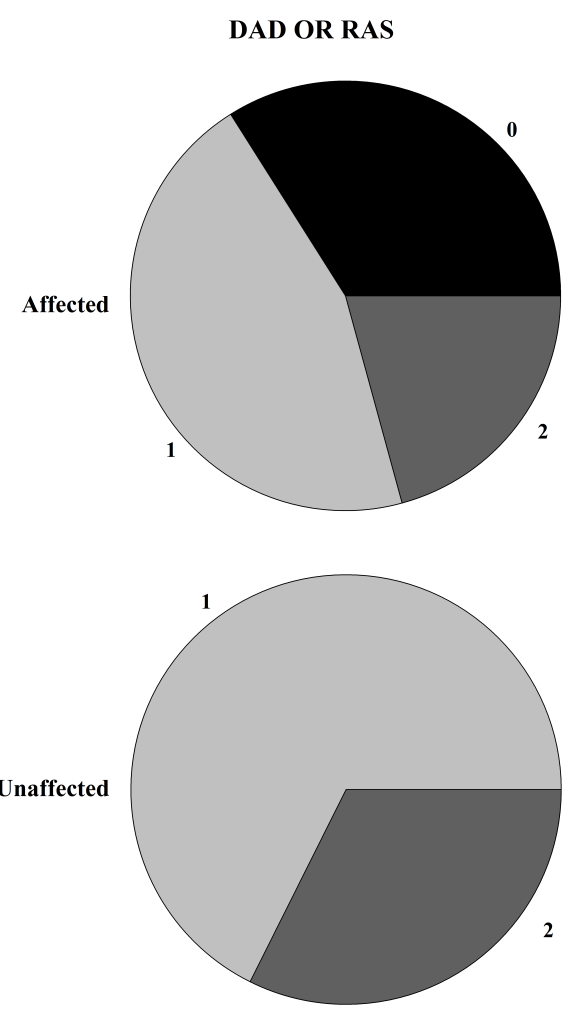

Fig. (2). Visual representation of HLA-DBQ*02 haplotype distribution $(2$ = Homozygosis, $1=$ Eterozygosis, $0=$ allele's absence) between individuals affected or unaffected by DED or RAS. If the DQ2 antigen is absent the $100 \%$ of patients show at least one signs between DED and RAS.

at least RAS or DED, while no appreciable difference was observed between those carrying one or two copies. To explain these results, anaylsis on the binding capacity to the pocket of HLA-DQ2 or HLA-DQ8 molecules on antigenpresenting cells [35] must be carried out. CD immunitary reactions are linked to the relationship established by this complex and CD4+ T cells causing tissue damage in the intestinal mucosa. This tissue damage seems to be correlated to an increasing presentation of gluten epitopes to T cells associated to the presence of the HLA heterodimer DQB $1 * 02$ which differ in their peptide binding affinity for gluten peptides [36]. This data explain why DQ2 homozygosis in intestinal mucosa is linked to a more marked intestinal flattening of the villi [13]; faced with these results we need to understand why the oral mucosa seem to have opposite behaviour.

This different response could be explained by the immunological and histological differences between the small intestine and the gut. The pathological alterations linked to celiac disease are correlated to T-cell activity in the presence of gliadin-derived peptide. This mechanism is well studied in the small intestine, where lymphocytes induce mucosal damage while the exact pathogenetic mechanism that leads to the development of lesions in the oral mucosa is still unknown.

There are many hypotheses about the different responses of intestinal or oral mucosa. The existence of different gliadin peptides that could provoke an immunological reaction depending on different anatomic or histological areas, the activity of oral bacteria as first participants in the enzymatic degradation of gliadin or the histological differences between the intestinal mucosal epithelium, consisting of single layered cuboidal cells compared to the stratified epithelium of the oral mucosa, which could explain the different concentration of gliadin-derived peptide [37, 38]. More accurate estimation and confirmation of the effect of specific HLA alleles require further evaluation in a larger sampling paying particular attention to the possible interaction of HLA loci with other genes (gene-gene interaction) [39]. Any possible further study could also focus on the application of more rapid, though more expensive, methods to obtain the HLA haplotype such as PCR-realtime [40].

Overall, our results suggest that genetic predisposition at the HLA-DQB1 locus, influences the formation of celiac oral signs in $\mathrm{CD}$ and could become a fundamental test for recognising underlying celiac forms. In conclusion, further studies will be necessary to establish if the role of oral pathology can be significant in identifying latent and atypical forms of celiac disease.

\section{ACKNOWLEDGEMENTS}

The authors received no specific funding for this article, and declare that no competing interests exist.

\section{CONFLICT OF INTEREST}

None Declare.

\section{REFERENCES}

[1] Clemente MG, De Virgiliis S, Kang JS, et al. Early effects of gliadin on enterocyte intracellular signalling involved in intestinal barrier function. Gut 2003; 52(2): 218-23.

[2] Dieterich W, Schuppan D. Is gliadin harmful from the first morsel? Dig Liver Dis 2007; 39(10): 917-21.

[3] Alaedini A, Green PH. Narrative review: celiac disease: understanding a complex autoimmune disorder. Ann Intern Med 2005; 142(4): 289-98.

[4] Barker JM, Liu E. Celiac disease: pathophysiology, clinical manifestations, and associated autoimmune conditions. Adv Pediatr 2008; 55: 349-65.

[5] Losowsky MS. A history of coeliac disease. Dig Dis 2008; 26(2): 112-20.

[6] Pastore L, Campisi G, Compilato D, Lo Muzio L. Orally based diagnosis of celiac disease: current perspectives. J Dent Res 2008; 87(12): 1100-7.

[7] Cassinotti A, Birindelli S, Clerici M, et al. HLA and autoimmune digestive disease: a clinically oriented review for gastroenterologists. Am J Gastroenterol 2009; 104(1): 195-217; quiz 194, 218.

[8] Ludvigsson JF, Brandt L, Montgomery SM. Symptoms and signs in individuals with serology positive for celiac disease but normal mucosa. BMC Gastroenterol 2009; 9: 57.

[9] da Silva PC, de Almeida Pdel V, Machado MA, et al. Oral manifestations of celiac disease: A case report and review of the literature. Med Oral Patol Oral Cir Bucal 2008; 13(9): E559-62.

[10] Schuppan D, Junker Y, Barisani D. Celiac disease: from pathogenesis to novel therapies. Gastroenterology 2009; 137(6): 1912-33.

[11] Kapitany A, Toth L, Tumpek J, et al. Diagnostic significance of HLA-DQ typing in patients with previous coeliac disease diagnosis based on histology alone. Aliment Pharmacol Ther 2006; 24(9):1395-402.

[12] Hunt KA, van Heel DA. Recent advances in coeliac disease genetics. Gut 2009; 58(4): 473-6.

[13] Jores RD, Frau F, Cucca F, et al. HLA-DQB1*0201 homozygosis predisposes to severe intestinal damage in celiac disease. Scand $\mathbf{J}$ Gastroenterol 2007; 42(1): 48-53. 
[14] Vona G, Bitti PP, Succa V, et al. HLA phenotype and haplotype frequencies in Sardinia (Italy). Coll Antropol 1997; 21(2): 461-75.

[15] Marrosu MG, Murru MR, Costa G, et al. Multiple sclerosis in Sardinia is associated and in linkage disequilibrium with HLA-DR3 and -DR4 alleles. Am J Hum Genet 1997; 61(2): 454-7.

[16] Scola L, Lio D, Candore G, et al. Analysis of HLA-DRB1, DQA1, DQB1 haplotypes in Sardinian centenarians. Exp Gerontol 2008; 43(2): 114-8.

[17] Lahteenoja H, Toivanen A, Viander M, et al. Increase in T-cell subsets of oral mucosa: a late immune response in patients with treated coeliac disease? Scand J Immunol 2000; 52(6): 602-8.

[18] Campisi G, Compilato D, Iacono G, et al. Histomorphology of healthy oral mucosa in untreated celiac patients: unexpected association with spongiosis. J Oral Pathol Med 2009; 38(1): 34-41.

[19] Armstrong MJ, Robins GG, Howdle PD. Recent advances in coeliac disease. Curr Opin Gastroenterol 2009; 25(2): 100-9.

[20] Mulder CJ, Hadithi MM, Rostami K, Goerres MS. Coeliac disease-has the time come for routine mass screening? in 2002-20102020? Rom J Gastroenterol 2002; 11(3): 179-82.

[21] Mearin ML, Ivarsson A, Dickey W. Coeliac disease: is it time for mass screening? Best Pract Res Clin Gastroenterol 2005; 19(3): 441-52.

[22] Ludvigsson JF, Montgomery SM, Ekbom A, Brandt L, Granath F. Small-intestinal histopathology and mortality risk in celiac disease. JAMA 2009; 302(11): 1171-8.

[23] Brousse N, Meijer JW. Malignant complications of coeliac disease. Best Pract Res Clin Gastroenterol 2005; 19(3): 401-12.

[24] Sugai E, Nachman F, Vaquez H, et al. Dynamics of celiac diseasespecific serology after initiation of a gluten-free diet and use in the assessment of compliance with treatment. Dig Liver Dis 2010; 42(5): 352-8.

[25] Malahias T, Cheng J, Brar P, Minaya MT, Green PH. The association between celiac disease, dental enamel defects, and aphthous ulcers in a United States cohort. J Clin Gastroenterol 2010; 44(3): 191-4.

[26] Pastore L, Carroccio A, Compilato D, Panzarella V, Serpico R, Lo Muzio L. Oral manifestations of celiac disease. J Clin Gastroenterol 2008; 42(3): 224-32.
[27] Ballinger A, Hughes C, Kumar P, Hutchinson I, Clark M. Dental enamel defects in coeliac disease. Lancet 1994; 343(8891): 230-1.

[28] Wierink CD, van Diermen DE, Aartman IH, Heymans HS. Dental enamel defects in children with coeliac disease. Int J Paediatr Dent 2007; 17(3): 163-8.

[29] Aine L, Maki M, Collin P, Keyrilainen O. Dental enamel defects in celiac disease. J Oral Pathol Med 1990; 19(6): 241-5.

[30] Erriu M, Boscarelli F, Peluffo C, et al. A rapid sample method for HLA haplotype typization. a preliminary study on celiac patients. Minerva Stomatol 2010; 59(9): 477-87.

[31] Liu E, Rewers M, Eisenbarth GS. Genetic testing: who should do the testing and what is the role of genetic testing in the setting of celiac disease? Gastroenterology 2005; 128(4 Suppl 1): S33-7.

[32] Clot F, Babron MC. Genetics of celiac disease. Mol Genet Metab 2000; 71(1-2): 76-80.

[33] Niewinski MM. Advances in celiac disease and gluten-free diet. J Am Diet Assoc 2008; 108(4): 661-72.

[34] Mina S, Azcurra AI, Riga C, Cornejo LS, Brunotto M. Evaluation of clinical dental variables to build classifiers to predict celiac disease. Med Oral Patol Oral Cir Bucal 2008; 13(7): E398-402.

[35] Wolters VM, Wijmenga C. Genetic background of celiac disease and its clinical implications. Am J Gastroenterol 2008; 103(1):1905.

[36] Heap GA, van Heel DA. Genetics and pathogenesis of coeliac disease. Semin Immunol 2009; 21(6): 346-54.

[37] Helmerhorst EJ, Zamakhchari M, Schuppan D, Oppenheim FG. Discovery of a novel and rich source of gluten-degrading microbial enzymes in the oral cavity. PLoS One 2010; 5(10): e13264.

[38] Lahteenoja H, Maki M, Viander M, et al. Local challenge on oral mucosa with an alpha-gliadin related synthetic peptide in patients with celiac disease. Am J Gastroenterol 2000; 95(10): 2880-7.

[39] van Heel DA, Hunt K, Greco L, Wijmenga C. Genetics in coeliac disease. Best Pract Res Clin Gastroenterol 2005; 19(3): 323-39.

[40] Reinton N, Helgheim A, Shegarfi H, Moghaddam A. A one-step real-time PCR assay for detection of DQA $1 * 05, \mathrm{DQB} 1 * 02$ and DQB $1 * 0302$ to aid diagnosis of celiac disease. J Immunol Methods 2006; 316(1-2): 125-32.

Received: July 27, 2011

Revised: August 22, 2011

Accepted: August 30, 2011

() Erriu et al.; Licensee Bentham Open.

This is an open access article licensed under the terms of the Creative Commons Attribution Non-Commercial License (http://creativecommons.org/licenses/by-nc/3.0/) which permits unrestricted, non-commercial use, distribution and reproduction in any medium, provided the work is properly cited. 